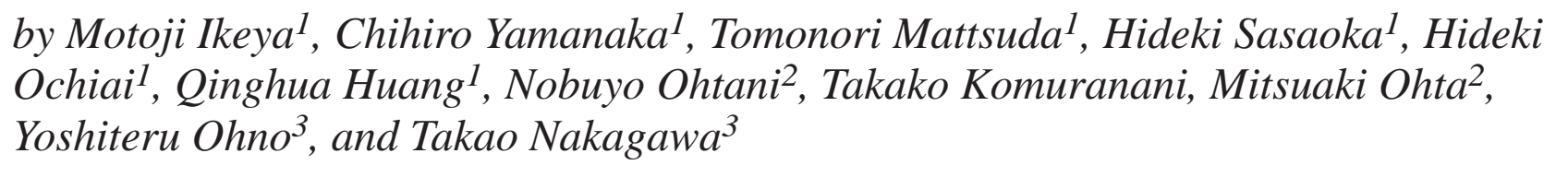

\title{
Electromagnetic pulses generated by compression of granitic rocks and animal behavior
}

\author{
1 Department of Earth and Space Science, Graduate School of Science, Osaka University, 1-1 Machikaneyama, Toyonaka, Osaka 560-0043, Japan. \\ 2 Department of Veterinary Physiology, College of Agriculture, Osaka Prefectural University, 1-1 Gakuen, Sakai, Osaka, Japan. \\ 3. Faculty of Engineering and Design, Kyoto Institute of Technology, Gosyokaidoucho, Matsugasaki, Sakyouku, Kyoto 606-8585, Japan. \\ 4 Department of Construction Engineering, Graduate School of Engineering, Osaka University, Yamada, Suita, Osaka, 565-0871, Japan.
}

Compression experiments on granite, basalt and marbles were made using a 500-ton compression machine with simultaneous detection of acoustic emission, electromagnetic (EM) waves. Attempts were made to reproduce unusual animal behavior before major earthquakes depicted in folklores and reported retrospectively in the M7.2 Kobe earthquake in 1995. Unusual animal behavior was observed during stress loading with simultaneous detection of pulsed EM waves prior to the detection of $A E$, but the judgement has to be partially subjective when animal behavior is discussed. Hence, hypothalamic chemicals in in-vivo brain and blood plasma of rats were analyzed before and after rock fractures. The enhanced noradrenaline and reduced adrenaline were observed, which was distinctively different from the reactions to other stresses but the same as that of exposures to EM waves. Unusual animal behavior would mostly be caused by pulsed EM waves.

\section{Introduction}

Unusual animal behavior before earthquakes have long been studied in Asia (Abe, 1934; Biophysics Institute, 1977; Rikitake, 1976; Bushirk et al., 1981; Ikeya, 1998), but rarely believed by Western geophysicists. A large number of reports on unusual animal behavior before the Kobe earthquake in 1995, Japan, were collected retrospectively (Wadatsumi, 1995). Similar reports from citizens were collected after the Izmit earthquake in Turkey and 921-earthquake in Taiwan in 1999 (Ikeya and Ulusoy, 2000). The birds were said to have disappeared from the neighborhood a few days before the earthquakes and the sky was unusually starry in Turkey. Swarms of earthworms appeared and deep sea fish, Trachipterus ishikawae, called messenger of dragon palace and earthquake fish by Taiwanese people, were captured before the 921-earthquake and before its aftershocks. Most scientists are skeptical of such precursors as unusual animal behavior and consider them superstition and afterthought.

The unusual animal behavior was earlier attempted to be explained by a hypothesis of serotonin syndrome caused by charged aerosol emanated from the epicenter (Tributsch, 1982). Reports on orientation of fish and silkworm before the Kobe earthquake sug- gested that unusual animal behavior might be responses to pulsed electromagnetic (EM) waves; they aligned perpendicular to pulse electric field in a simulation experiment (Ikeya, 1996a,b). The electric field intensities of the preseismic EM pulses at different locations around the epicenter of the Kobe earthquake in 1995 were estimated from the reports and experiments of electric field effects on animals (Ikeya et al., 1997).

Stories of spontaneous switching-on of radio and TV's and stopping or rapid moving of quartz-clock hands, which were reported to have occurred before the Kobe earthquake (Ikeya et al., 1998) and Izmit earthquakes, also suggested the appearance of intense seismic EM waves. These were reproduced in the laboratory using pulsed EM waves; the malfunctioning has been suggested to be caused by seismic electromagnetic signals (SEMS) of about 10 $\mathrm{W} / \mathrm{m}^{2}$ before the main shock (Huang and Ikeya, 1997; Ikeya et al., 1998).

These reports linked the electric field of preseismic EM waves with unusual animal behavior and malfunctioning of home electric appliances before earthquakes (Ikeya, 1998). However, they failed to remove the skepticism of scientists over linking the unusual animal behavior before earthquakes with any physical realities. Most scientists regard unusual animal behavior as psychological "selective recognition" linking trivial matters with earthquakes according to legends in Oriental culture. More persuasive work must be done to prove whether the legends on earthquake precursors can be treated as true phenomena before earthquakes by simulating an earthquake with rock compression and fracture.

Rock fractures generate EM phenomena (Brady and Rowell, 1986). Only one preliminary report on animals is in the Proceedings of the International Conference on Abnormal Animal Behavior Prior to Earthquakes, in which a small rock of gabbro was compressed beside mice and their behavior was recorded (Gawthrope et al., 1978). Mice looked exhibiting fear by freezing postures ahead of fracture. Somehow, no serious work seems to have been done in these two decades since the preliminary work in spite of the fact that our understanding of brains has progressed considerably. Interdisciplinary collaboration with animal biologists with modern methods of physical and chemical analysis is needed in this type of work.

The techniques for detecting pulsed EM waves have also been developed as to allow us to use a convenient digital storage oscilloscope (DSO), which was used to detect preseismic electric pulses inducing peculiar behavior in animals (Ikeya et al, 1997a) but failed to link the signal with the earthquake that followed.

We have done some preliminary study of unusual animal behavior during the rock compression using compression machines in the construction engineering. The animal behavior during the compression in some experiments was broadcasted in NHK TV programs of "Science Eye" (Jan. 17, 1998) and "Interesting Scientist's 
Life" in Japan as well as in BBC program of "Tomorrow's World Earthquake Animals" (Sept. 23, 1998). Programs of "Sense of Disaster" by Granada TV and "Super Nature" by R. Watson in British Channel 5 dealt with the unusual animal behavior and our obsrvation on the EM responses of catfish and plants. A cat sleeping at night waked up and mewed sorrowfully when EM pulses caused by discharges using a Van de Graaff generator in the next room. She went out of the room and came back surprisingly with the socks of the owner in her mouth. These were filmed for the TBS program of "Fantastic Animals". Snakes and beetles sleeping in winter came out by the EM pulses. General public and therefore mass media are very much interested in the topic, but scientists are reluctant to deal with the matter in scientific journals by saying that what lay citizen observed cannot be the objects of scientific study.

No experimental work has been published on the neurotransmitters of animals showing unusual behavior during the compression and fracture of rocks simulating earthquakes. Present interdisciplinary work made in collaboration between veterinary physiologists, construction engineers and physicists describes the observation of EM waves, acoustic emissions (AE) together with the observation of the behavior of several animals during the compression and fracture of about 25 rocks using a 200-ton and 500-ton compression machines. Chemical analyses of blood plasma of rats placed nearby the compression machine indicated reduced adrenaline and enhanced noradrenaline, the same response as caused by the exposure to EM waves.

\section{Experimental}

\section{Rock and animals}

Rocks of granite, marble and basalt of the size $15 \times 15 \times 30 \mathrm{~cm}^{3}$ attached with strain gauges and piezo-elements for AE were fractured using a 500-ton compression machine to simulate earthquakes. Granitic rocks were heated at different temperatures of 200, 300 and $400{ }^{\circ} \mathrm{C}$ or immersed in water to study the effect of moistures.

Two budgerigars, six rats and six mice were placed in cages, two eels in aquariums and eleven silkworms at a distance of $1 \mathrm{~m}$ from the rock. Their behavior was recorded with a video camera. Conscious male Sprague-Dawley rats, 250-350 g in weight, were also used in the experiment on the blood analyses.

\section{Analysis of blood plasma}

The ventromedial hypothalamus, i.e., a rostral center of the sympathetic nervous system, was perfused with the artificial cerebrospinal fluid ( $\mathrm{NaCl} 147 \mathrm{mM}, \mathrm{CaCl}_{2} 2.3 \mathrm{mM}, \mathrm{KCl} 4 \mathrm{mM}, \mathrm{pH}$ 5.9-6.0) at 1.0 $\mathrm{ml} /$ min using a microinfusion pump (CMA-100). Perfusate was collected into Eppendorf tubes kept on ice and measured by a high precision liquid chromatography (Ohtani et al., 1997). Adrenaline, noradrenaline and serotonin in blood taken from pre-cannulated conscious rats were measured before and after the fracture of granite and also before and after the exposure to EM waves at 200-300 MHz. Experiments were done following the "Principles of Animal Care" and other regulations.

\section{Detection of electromagnetic (EM) waves}

A one-turn loop antenna resonating at $228 \mathrm{MHz}$ has been used to detect EM pulses with a wide-band amplifier and a storage oscilloscope (Iwatsu TS8422) with a bandwidth of $400 \mathrm{MHz}$. An active rod antenna was connected to a booster and to an electric field-meter at $30 \mathrm{MHz}$ with the bandwidth of $9 \mathrm{kHz}$. In some cases, all detectors, animals and the sample rock as well as recording video camera were placed inside the $1 \mathrm{~mm}$ thick aluminum shield box of the size $1.21 \times 1.46 \times 1.21 \mathrm{~m}^{3}$ which covered the head of a compression machine. Another loop antenna, the storage oscilloscope and moni- toring TV were placed outside the shield to observe the ambient EM noise and animal behavior.

\section{Results and discussion}

\section{Compression and fracture experiments}

The strain increased linearly as the load increased. The rock was fractured when the load was close to 300 tons (stress of about $1.5 \times 10^{8} \mathrm{~Pa}$ ) with strain of $2 \times 10^{-3}$. Both EM and AE pulses were generated by the compression presumably due to microfracture of rocks. Pulses of EM waves having an envelope of about $30 \mathrm{~ns}$ in width and intensity of $10-50 \mathrm{mV} / \mathrm{m}$ were observed at higher frequencies than $100 \mathrm{MHz}$ from $10 \mathrm{~min}$ (60 tons). The background level lower than $30 \mathrm{MHz}$ showed no change during the experiment. The AE was detected from $35 \mathrm{~min}$, much later than the EM waves at a strain larger than $1.5 \times 10^{-3}$. Figure 1 shows the observed stress, strain, $\mathrm{AE}$ and $\mathrm{EM}$ waves as a function of time after the start of compression.

\section{Animal behavior and EM waves}

Animals were acclimatized with the environment beforehand to see their behavior during compression. They were completely inert

granite

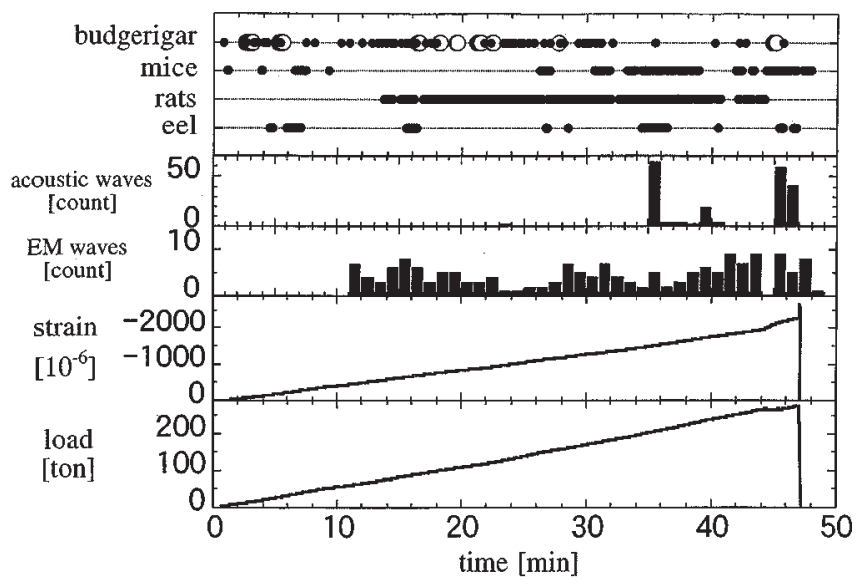

Figure 1 Variation of stress (load in tons) and strain for granite using the 500-ton compression machine together with the observation of electromagnetic (EM) pulses, acoustic emissions $(A E)$ as a function of time after loading. Movements of animals are also indicated.

before the compression. No distinct difference in the animal behavior was observed during the rock compression in a short time of 15 minutes from the start to the fracture at about $1.5 \times 10^{8} \mathrm{~Pa}$; the compression rate was $10^{7} \mathrm{~Pa} / \mathrm{min}$. A slow rate of stress increase of about $2.5 \times 10^{6} \mathrm{~Pa} / \mathrm{min}$ was necessary from the start of compression to the fracture to generate the unusal animal behavior and EM pulses. Figure 1 also shows the behavior of several animals as a function of compression time.

Budgerigars twittered and fluttered out of the porch as indicated by dots and open circles, respectively. Mice looked scared by exhibiting freezing postures as reported in the early work (Gawthrope et al., 1978). Sleeping rats woke up, stood up, looked to keep vigil, groomed restlessly when the load on the rock was above 60 tons. They also washed their face nervously in the same way as under the stimuli of pulsed field of $2 \mathrm{~V} / \mathrm{m}$ applied to the wet floor (Ikeya et al., 1997b) and exposure to EM waves of about $0.01 \mathrm{~W} / \mathrm{m}^{2}$ and to EM pulses by discharges using a Van de Graaff high voltage generator (Ikeya, 1998). Hamsters groomed and then bit each other, which were also caused by electric stimuli (Ikeya et al., 1997a) and retrospectively reported to have been observed before the Kobe 
earthquake. They stopped these activities after the fracture of the rock.

The detection of EM waves accompanied these behaviors well before the fracture at about 300 ton. Eels moved restlessly and looked as if shocked when EM waves at the antennas were detected in oscilloscope as shown in Figure 2. The calibration indicated that the intensity of the EM pulse was about $2 \mathrm{~V} / \mathrm{m}$, which is above the saturation level of a rod antenna of $0.7 \mathrm{~V} / \mathrm{m}$ and less than that of a loop antenna, $5 \mathrm{~V} / \mathrm{m}$. The corresponding magnetic field was $6.7 \mathrm{nT}$ and the power density was $10^{-2} \mathrm{~W} / \mathrm{m}^{2}$, which was intense enough to agitate the sea lions in the Kobe-Oji Zoo and crocodiles in the Banana-Alligator Garden (1997a). Catfish with electrosensory organs would also be agitated, but the electric field was less than marginal intensity for ordinary fish to respond; ordinary fish aligned or shocked at about $10 \mathrm{~V} / \mathrm{m}$ (Ikeya et al., 1996).

Animal behavior was not clear and the detection of EM waves were not prominent when granitic rock samples were pre-heated at $200-500{ }^{\circ} \mathrm{C}$ or immersed in water for 12 hours before the experiment. Slight EM pulses and little unusual behavior were observed when basalt and marble were broken.
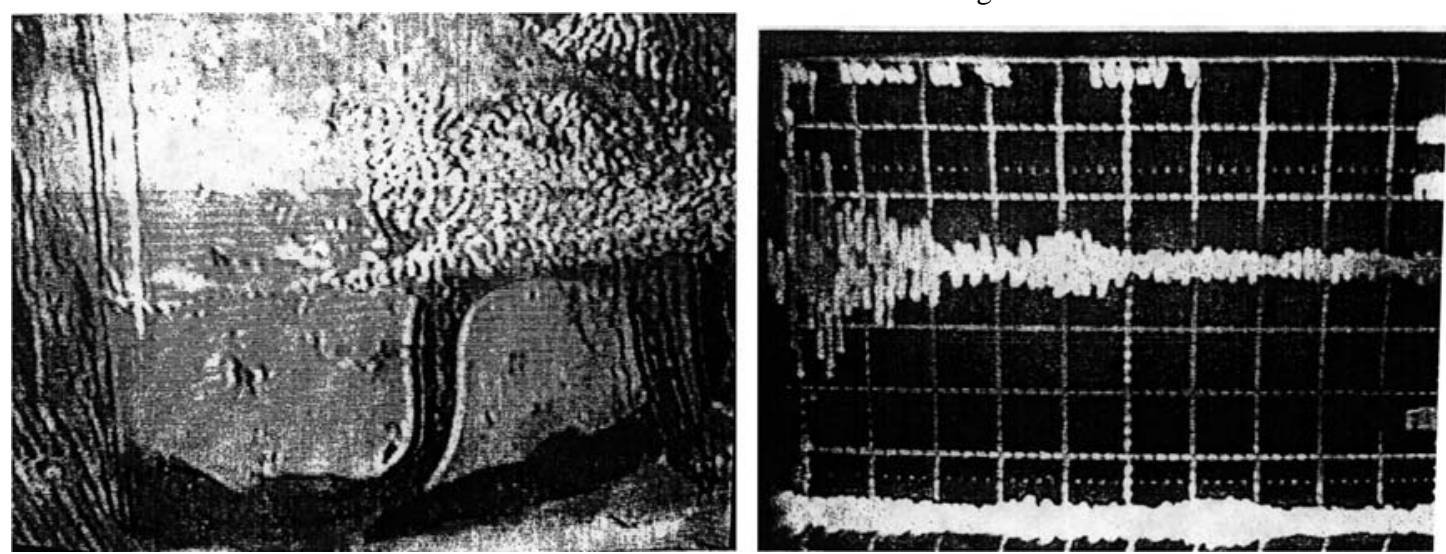

Figure 2 Oscilloscope display of EM waves detected by loop and rod antennas together with a video picture of eel.

It is difficult to link these results directly with the reported unusual animal behavior before earthquakes. Correlating animal behavior with detection of EM pulses is not straightforward in these experiments, though EM pulses are so far considered to be the most probable cause of unusual animal behavior. Undetected weak AE sounds might also be responsible. Judging some animal behavior as unusual was also criticized to be subjective and not scientific. Hence, chemical substances in rat's blood were investigated to know the changes before and after the exposures to EM waves and to rock compression.

\section{Analysis of rat plasma}

Figure 3 shows that the concentration of plasma noradrenaline, an indicator of a state of excitement, increased both after the fractures of granite and after exposure to EM waves. In contrast, adrenaline, which is an index of uneasiness, decreased somehow after both events. The latter is released from the adrenal medulla by a stimulation of the sympathetic nervous system. Statistical multifactor analysis of variance and Duncan's multiple range test in the stress analysis were used by setting the significance, $p=0.05$ (Ohtani et al., 1997).

The response to EM waves and to the compression of granite is different from the reaction to other stresses such as heat, sounds and light. The detection of conventional physical quantities is made with a particular organ and its nervous systems, but all organs and their nervous system would be disturbed by the current which EM pulses induced. Adrenaline may be decreased by EM pulses by the reduction of the sense of uneasiness.

Hypothalamic concentration of serotonin, noradrenaline and $\gamma$ aminobutyric acid were fluctuated by exposure to EM waves and might be connected with that of plasma noradrenaline. The changes in the hypothalamic concentration caused by granite compression experiments were different from those exposed to temperature and mechanical stimuli (Ohtani et al., 1997), but very similar to those exposed to EM waves. Levels of dopamine and serotonin remained unchanged by the treatments contrary to the proposal that "serotonin syndrome" caused by the exposure to charged aerosol was the cause of unusual animal behavior (Tributsch, 1982).

\section{Animal behavior and EM pulses}

Unusual grooming of birds and rats, shocked movements of eels, peculiar heading up and alignments of silkworms were observed in the fracture experiments of granitic rocks using compression machines with the simultaneous detection of EM waves at the loop and rod antennas. Both phenomena started after more than ten minutes compression (about 70 tons or $3 \times 10^{7} \mathrm{~Pa}$ ) well before the fractures at $47 \mathrm{~min}$ (about 280 tons or $10^{8} \mathrm{~Pa}$ ). The detection of AE by piezoelectric sensor attached to the rock was also later than the start of EM waves. Observation indicates that unusual animal behavior and generation of EM waves are common phenomena before the main rupture of granitic rock.

Some precursor phenomena observed by lay people, which were said to have occurred 8 days before and also from a few hours to one hour before the Kobe earthquake, might thus be caused by the pulsed EM waves during local microcrack formation in granitic bedrocks ahead of the major shock. It is of interest to note that EM waves at ultra low frequency (ULF) of $0.01 \mathrm{~Hz}$ observed before the 1989 Loma Prieta earthquake started 12 days before and peaked 8 days before, some quiescence followed and then had a peak a few hours before the earthquake (Frazer-Smith, 1990). The tendency of unusual animal behavior and generation of EM pulses during the compression experiment followed the similar processes in a different time scale. The EM waves at ULF before earthquakes might have resulted from an envelope of overlapping EM pulses.

One of the objections to the work on the unusual animal behavior was the absence of the observational data of intense EM signal as observed in this work. Earth potential measurements as known in the Greek VAN method gave $10^{-5} \mathrm{~V} / \mathrm{m}$ for magnitude 5-6 at $100 \mathrm{~km}$.
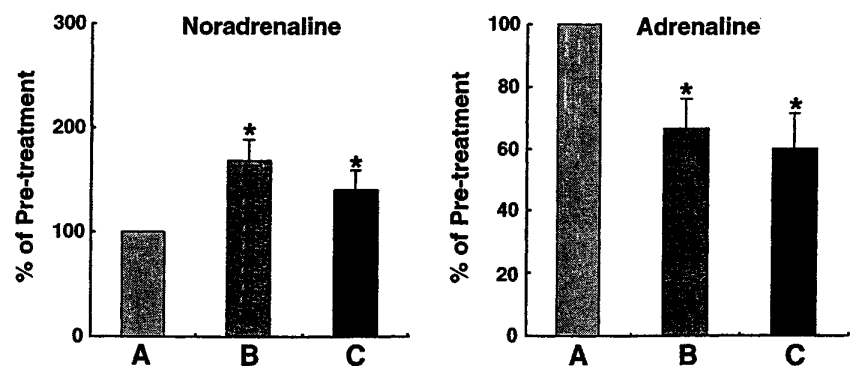

Figure 3 Plasma levels of noradrenaline and adrenaline in the blood plasma of rats before the compression and EM exposure experiments (A:100\%), after exposure to EM waves at $300 \mathrm{MHz}$ and $10 \mathrm{~W} / \mathrm{m}^{2}(B)$ and to granite fracture using a 500-ton compression machine $(C)$. The means and standard errors of 3-4 animals are given with the significance $(p<0.05)$ by asterisks. 
Magnetic anomalies of $100 \mathrm{nT}$ before a big earthquake would correspond to the electric field of $30 \mathrm{~V} / \mathrm{m}$ if that is magnetic field of EM waves. It must be noted that the electric field of $2 \mathrm{~V} / \mathrm{m}$, i.e., the magnetic field of $6.7 \mathrm{nT}$ during the rock compression in this work is for pulses with the width much less than $0.1 \mathrm{~ms}$ using digital storage oscilloscopes. This intensity is sufficiently high to surprise sensitive animals (Ikeya, 1998). It is known that aquatic animals like sharks and catfish with electrosensory organ can detect $10^{-5} \mathrm{~V} / \mathrm{m}$ to capture prey animals and to communicate with each other (Bastian, 1994). Sensitive animals like budgerigar and crocodiles showed unusual behavior by the field of $0.3 \mathrm{~V} / \mathrm{m}$ (magnetic field of $1 \mathrm{nT}$ ) for the persistence of $0.1 \mathrm{~ms}$.

\section{Conclusion}

Unusual animal behavior during the compression of rocks was observed together with detection of EM pulses and was confirmed by blood analysis. Monitoring seismo-electromagnetic pulses and determination of their source using GPS (Global positioning system) clocks should be made in real time by removing EM noises due to lightning and human artifact. Some storage oscilloscope with a trigger level should be used at a high sampling frequency of at least 10 $\mathrm{MHz}$. One can detect pulses with the width of about $0.1 \mathrm{~ms}$ which have been broadened during propagation; a high frequency component decays due to a small skin depth. These EM pulses will be used as an early earthquake warning to reduce sufferings accompanying the disaster though the exact time of earthquakes would still be difficult to predict. Animal behavior similar to those induced by pulsed electric field and EM exposures and so by lightning in nature could be a useful warning to lay citizens in earthquake prone areas even admitting the difficulties of deterministic earthquake prediction using these EM signals.

\section{Acknowledgments}

We thank Prof. N. Kajiwara at Kobe Women's College, members of the laboratory for their help, Dr. Kundu for his critical reading of the manuscript and the Kansai Energy Recycle Research Foundation (KRF) for the Grant 1998-2000. We also thank the referee for constructive comments and suggestions.

\section{References}

Abe, N., 1934, On the behavior of catfish in response to galvanic stimuli: Sci. Rep. Tohoku Imp. Univ. Biol. v. IX, pp. 87-96.

Bastian, J. (1994): Aquatic animals with extraordinary sensitive electric receptors. Phys. Today 47, 30-37.

Biophysics Institute, Academica Sinica ed., 1977, Animals Informs Earthquake: Beijing China. Japanese translation published by Nagasaki Publisher.

Brady, B.T. and Rowell, G.A., 1986, Laboratory investigation of the electrodynamics of rock fracture: Nature v. 321, pp. 488-492.

Bushirk, R.E., Frohlich, C. and Latha G.V., 1981, Unusual animal behaviors before earthquakes: A review of possible sensory mechanisms: Rev. Geophys. \& Space Phys. v.19, pp. 247-270
Frazer-Smith, A.C., Bernardi, A. McGrill, P.R. Ladd, M.E. Helliwell, A. and Villard, O.G., 1990, Low frequency magnetic field measurements near the epicenter of the Ms 7.1 Loma Prieta earthquake. Geophys. Res. Lett. v. 17 , pp. $1465-1468$.

Gawthrope, W.H., Johnson, R., Haberman, R.F., and Wyss, M., 1976, Preliminary experiments on behavior of mice before rock failure in laboratory, in Proc. Abnormal Animal Behavior Prior to Earthquakes (U. S. G. S,) pp. 205-212.

Huang, Q. and Ikeya, M., 1997, Electric field effects on animals: Mechanism of seismic anomalous animal behavior (SAAB): Earthquake Research in China v. 11, pp. 109-118.

Ikeya, M., Takaki, S. \&Takashimizu, S., 1996a, Electric shocks for seismic animal anomalous behaviors (SAABs). J. Phys. Soc. Japan v. 65, pp. 710713.

Ikeya, M., Huruta, H., Anzai, H. and Kajiwara, N. (1996b): Electric field effects on rats and sparrows for seismic animal anomalous behavior (SAAB). Jpn J. Appl. Phys. v. 65, pp. 4587-4594.

Ikeya, M., Komatsu, T., Kinoshita, Y., Teramoto, K., Inoue, K. Gondou, M. and Yamamoto, T., 1997, Seismically-induced anomalous animal behavior (SAAB): Electric field before earthquakes at Kobe-Oji Zoo and IzuAtagawa Tropical Banana-Alligator Garden. Episode v. 20, pp. 235-241.

Ikeya M., Matsuda, T. and Yamanaka, C., 1998, Reproduction of mimosa and clock anomalies before earthquakes: Are they "Alice in Wonderland Syndrome" ? Proc. Japan Acad. v. 74, Ser. B pp. 60-64.

Ikeya, M., 1998. Why Do Animals Behave Unusually Before Earthquakes ? Tokyo, NHK Publisher (in Japanese); Chinese ed. Translated by Huang, C. from Sueichan Press, Taiwan in 2000.

Ikeya, M. and Ulusoy, U., 2000, Unusual phenomena before the Izmit and Taiwan earthquakes in 1999. In preparation.

Ohtani, N, Ohta, M and Sugano, S, 1997, Microdialysis of hypothalamic modification of neurotransmitters in rats. J. Neurochem. v. 69, pp. 16221628.

Rikitake, T., 1976, Earthquake Prediction: Elsevier, Amsterdam, pp357.

Tributch, H., 1982, When the Snakes Awake, New York, MIT Press. pp 248.

Wadatumi, K., 1995, 1591 Witnesses Prior to Earthquake: Tokyo Pub, Tokyo, pp. 267 in Japanese.

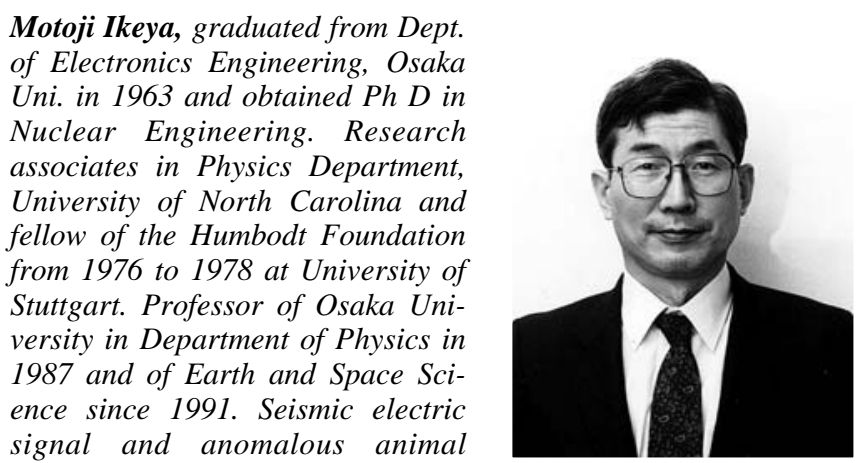

\begin{abstract}
the Kobe Earthquake.
Motoji Ikeya, graduated from Dept. Uni. in 1963 and obtained Ph D in University of North Carolina and fellow of the Humbodt Foundation from 1976 to 1978 at University of Stuttgart. Professor of Osaka Unience since 1991. Seismic electric signal and anomalous animal
\end{abstract}

